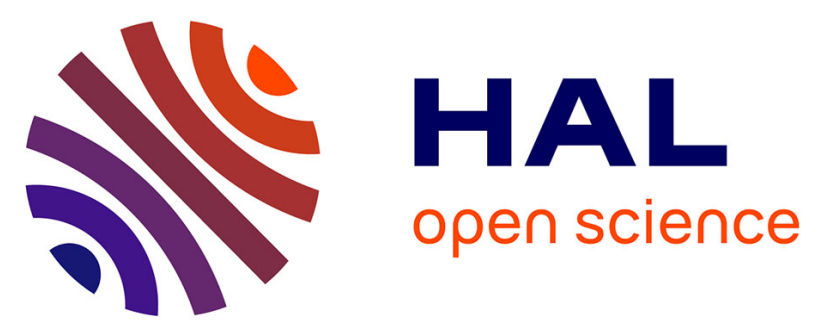

\title{
Bare laser-synthesized Au-based nanoparticles as nondisturbing surface-enhanced Raman scattering probes for bacteria identification
}

\author{
Martin Kögler, Yury Ryabchikov, Sanna Uusitalo, | Alexey Popov, Anton \\ Popov, Gleb Tselikov, Anna-Liisa Välimaa, Ahmed Al-Kattan, Jussi Hiltunen, \\ Riitta Laitinen, et al.
}

\section{To cite this version:}

Martin Kögler, Yury Ryabchikov, Sanna Uusitalo, | Alexey Popov, Anton Popov, et al.. Bare laser-synthesized Au-based nanoparticles as nondisturbing surface-enhanced Raman scattering probes for bacteria identification. Journal of Biophotonics, 2018, 11 (7), pp.e201700225. 10.1002/jbio.201700225 . hal-02137908

\section{HAL Id: hal-02137908 \\ https://hal-amu.archives-ouvertes.fr/hal-02137908}

Submitted on 23 May 2019

HAL is a multi-disciplinary open access archive for the deposit and dissemination of scientific research documents, whether they are published or not. The documents may come from teaching and research institutions in France or abroad, or from public or private research centers.
L'archive ouverte pluridisciplinaire HAL, est destinée au dépôt et à la diffusion de documents scientifiques de niveau recherche, publiés ou non, émanant des établissements d'enseignement et de recherche français ou étrangers, des laboratoires publics ou privés.

\section{(c)(1)}

Distributed under a Creative Commons Attribution| 4.0 International License 


\title{
Bare laser-synthesized Au-based nanoparticles as nondisturbing surface-enhanced Raman scattering probes for bacteria identification
}

\author{
Martin Kögler $^{1,2}$ (1) | Yury V. Ryabchikov ${ }^{3,4}$ | Sanna Uusitalo ${ }^{5}$ | Alexey Popov ${ }^{6,7}$ | Anton Popov ${ }^{3}$ | \\ Gleb Tselikov ${ }^{3}$ | Anna-Liisa Välimaa ${ }^{8}$ | Ahmed Al-Kattan ${ }^{3}$ | Jussi Hiltunen ${ }^{5}$ | Riitta Laitinen ${ }^{9}$ | \\ Peter Neubauer $^{2}$ | Igor Meglinski ${ }^{6,7,10}$ | Andrei V. Kabashin ${ }^{3,10 *}$ (D)
}

${ }^{1}$ Drug Research Program, Division of Pharmaceutical Biosciences, Centre for Drug Research, University of Helsinki, Helsinki, Finland

${ }^{2}$ Chair of Bioprocess Engineering, Institute of Biotechnology, Technische Universität Berlin, Berlin, Germany

${ }^{3}$ Aix-Marseille Univ, CNRS, Marseille, France

${ }^{4}$ P.N. Lebedev Physical Institute of Russian Academy of Sciences, Moscow, Russia

${ }^{5}$ VTT - Technical Research Centre of Finland, Oulu, Finland

${ }^{6}$ Optoelectronics and Measurement Techniques, Faculty of Information Technology and Electrical Engineering, University of Oulu, Oulu, Finland

${ }^{7}$ ITMO University, St. Petersburg, Russia

${ }^{8}$ National Resources Institute Finland (LUKE), Bio-based Business and Industry, University of Oulu, Oulu, Finland

${ }^{9}$ Natural Research Institute Finland (LUKE), Biobased Business and Industry, Turku, Finland

${ }^{10}$ National Research Nuclear University "MEPhI", Institute of Engineering Physics for Biomedicine (PhysBio), Moscow, Russia

*Correspondence

Andrei V. Kabashin, Aix-Marseille Univ, CNRS, LP3, Marseille, France.

Email: kabashin@1p3.univ-mrs.fr

Funding information

Academy of Finland through, Grant/Award number: FOULSENS project (1292253); COST project, Grant/Award number: ECOST-STSMBM1205-120416-072252; from Center for Research Strategy of Free University of Berlin, Grant/Award number: 0503121810; Government of Russian Federation, Grant/Award number: Grant 074-U01; ITMO "Plan Cancer 2014-2019" INSERM program, Grant/Award number: "LASERNANOCANCER" (No. PC201420) and GRAVITY projects; Academy of Finland;
The ability of noble metal-based nanoparticles (NPs) (Au, Ag) to drastically enhance Raman scattering from molecules placed near metal surface, termed as surface-enhanced Raman scattering (SERS), is widely
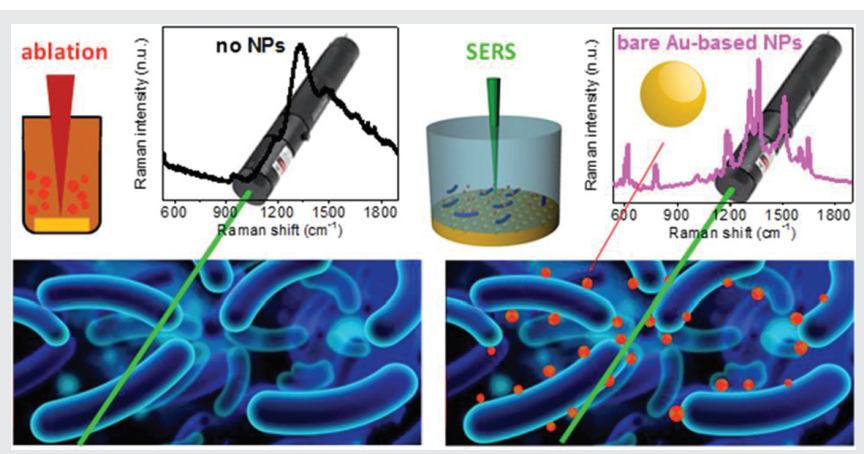
used for identification of trace amounts of biological materials in biomedical, food safety and security applications. However, conventional NPs synthesized by colloidal chemistry are typically contaminated by nonbiocompatible by-products (surfactants, anions), which can have negative impacts on many live objects under examination (cells, bacteria) and thus decrease the precision of bioidentification. In this article, we explore novel ultrapure laser-synthesized Au-based nanomaterials, including Au NPs and AuSi hybrid nanostructures, as mobile SERS probes in tasks of bacteria detection. We show that these Au-based nanomaterials can efficiently enhance Raman signals from model R6G molecules, while the enhancement factor depends on the content of $\mathrm{Au}$ in NP composition. Profiting from the observed enhancement and purity of laser-synthesized nanomaterials, we demonstrate successful identification of 2 types of bacteria (Listeria innocua and Escherichia coli). The obtained results promise less disturbing studies of biological systems based on good biocompatibility of contamination-free laser-synthesized nanomaterials.

\section{KEYWORDS}

bacteria detection, laser ablation in liquids, Raman spectroscopy, SERS, ultrapure laser-synthesized Au nanoparticles 
Academy of Finland; European Cooperation in Science and Technology, Grant/Award number: BM1205-120416-072252; Academy of Finland, Grant/Award numbers: projects 260321, 290596, M-SPEC project (284907)

\section{1 | INTRODUCTION}

Raman scattering is known to provide a variety of information on the structure and composition of the matter, based on its vibrational fingerprints, and this information can be used for highly precise identification of chemical or biological species [1]. Although Raman scattering is a very weak phenomenon, its cross section can be enhanced by many orders of magnitude by using noble metal $(\mathrm{Ag}, \mathrm{Au})$ nanostructures $[2,3]$. The latter modality, termed as surfaceenhanced Raman scattering (SERS), is based on the property of the metals to support oscillations of free electrons (plasmons) under optical excitation. Such plasmonic oscillations can amplify local electric field near the metal surface and thus drastically enhance Raman signals from target molecules placed near the metal $[2,3]$. In particular, Raman spectroscopy (RS) has been adapted for the detection of bacteria species and the analysis of bacteria spores [4, 5]. The identification of bacteria is typically based on the detection of some specific organic molecules (bacterial "fingerprints") on the surface of the bacterial membrane via their unique Raman spectra [4]. In SERS modality of bacteria detection, irregular or patterned metal substrates or metal nanocolloids of different shape and size are normally used for signal enhancement in order to lower the detection limit of this method [5-19]. Such metal nanostructures adsorb to the surface of bacteria and provide information on molecular structures of the cell wall around the bacteria. It is important that SERS signals are unaffected by water, a significant component of biological cells or bacteria, while the presence of metal can quench auto-fluorescence, which is always present as a background in biological systems [4, 5].

However, conventional $\mathrm{Au}$ or $\mathrm{Ag}$ nanoparticles (NPs) synthesized by chemical methods, such as the reduction of a gold precursor in the presence of a capping ligand [20,21], have some limitations for studies of live objects such as cells and bacteria. The problem is that nanomaterials prepared by chemical methods are typically contaminated by nonreacted starting reagents, by-products, anions and surfactants, as well as often covered by stabilizing ligands [22, 23]. As shown in many studies (see, refs. [24-27]), the use of such nanomaterials can be accompanied by a drastic aggravation of proliferation and viability of bacteria and cells under study. In other words, chemically synthesized NPs are often disturbing for live bacterial or cell cultures under examination that decreases the precision of SERS-based identification. In addition, SERS signals can be strongly affected by parasitic noise signals from the contaminants of NPs- stabilizing ligands, which complicate biomolecular identifications under ultra-low concentrations of target material.

Pulsed laser ablation in liquids (PLAL) has recently emerged as a physical alternative to conventional synthesis [28-32], which promises a solution of the contamination problem of chemically synthesized nanomaterials. This method is based on laser radiative removal (ablation) of material from a solid target in a liquid ambience, leading to a natural production of nanoclusters and their subsequent coalescence to form colloidal NPs solutions [33, 34]. As a huge advantage of this method, laser ablation can be performed in ultrapure environment (e.g., in deionized water), which excludes any toxic contaminant on the surface of synthesized nanomaterials [33]. Furthermore, using methods of ultrashort laser ablation [29, 30] or fragmentation [35, 36], one can prepare extremely stable aqueous solutions of "bare" (ligand-free) Au NPs having unique surface chemistry [37] and different reactivity [38, 39] compared to conventional colloidal nanomaterials. The absence of ligands and contaminants on the surface of such Au-based NPs gives a promise for their successful use as mobile probes for SERS applications and their efficiency in such tasks was recently confirmed in our studies [40, 41]. Moreover, despite the absence of any biopolymer coating such "bare" $\mathrm{Au}$ NPs were found to have relatively low toxicity and a good cell uptake, which promises their successful use in live systems [42].

It should be noted that the versatility of laser-ablative technique allows for an easy synthesis of a variety of alternative materials and composite structures, including nanomaterials having excellent compatibility with biological systems. Crystalline silicon ( $\mathrm{Si}$ ) is a prominent example of such material, which is one of the essential elements in live organism and is present in many biological tissues in the form of orthosilicate $\left(\mathrm{SiO}_{4}{ }^{4-}\right)$ [43]. We recently showed that contamination-free laser-synthesized $\mathrm{Si}$ NPs are not only well compatible with biological systems in vitro and in vivo $[44,45]$, but are also biodegradable as they decay in aqueous environment into orthosilicic acid $\mathrm{Si}(\mathrm{OH})_{4}$ and excrete from biological systems without any harmful effects [46]. We envision that the coating of plasmon-supporting SERS probes by Si shell could improve the compatibility of these probes with biological systems and bring novel functionalities. We recently showed the possibility for synthesizing such hybrid Au-Si nanostructures with controlled content of Si in NPs composition [47].

In this article, we employ bare (ligand-free) Au-based nanomaterials, including pure $\mathrm{Au}$ and AuSi core-shell NPs, 
synthesized by methods of laser ablation in deionized water, as SERS probes and access their efficiency in tasks of bacteria identification.

\section{2 | MATERIALS AND METHODS}

\section{1 | Laser fabrication of Au-based nanomaterials for SERS}

The synthesis of pure Au NPs and Au-Si composite structures was described in detail in our previous studies [29, 30, 47]. Briefly, for the fabrication of pure Au NPs, radiation from a Ti:Sapphire laser (Hurricane Spectra Physics Laser, 110 femtosecond pulse duration, $800 \mathrm{~nm}$ wavelength, $1 \mathrm{kHz}$ repetition rate, Mountain View, CA, USA) was focused by a
$50 \mathrm{~mm}$ focal distance lens onto a gold target (99.99\%) immersed in $10 \mathrm{~mL}$ solution of deionized water (18 $\mathrm{M} \Omega$ ) and placed $20 \mathrm{~mm}$ below the liquid surface level. A platform containing the target in a liquid vessel was constantly moved in order to avoid ablation from the same area on the target surface. A solution of bare Au NPs was typically obtained after 20 minutes of irradiation onset and this process was accompanied by its deep red coloration. As follows from transmission electron microscopy (TEM) analysis (Figure 1A), the mean size of Au NPs prepared by this method was about $25 \mathrm{~nm}$. To prepare solutions of Au-Si hybrid structures with controllable Au content, we first prepared a solution of bare Si NPs in deionized water. Here, a Si wafer ((100), N-doped, 1-10 $\Omega \mathrm{cm}$ ) was ablated by the Ti:Sapphire laser similar to how it was done in the case of

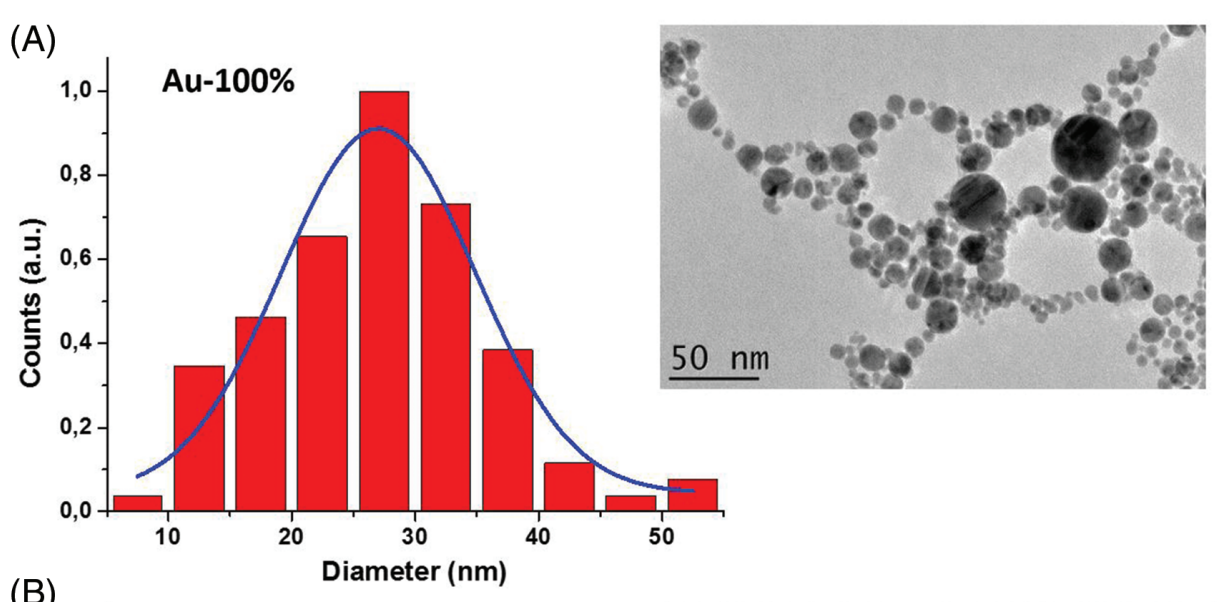

(B)
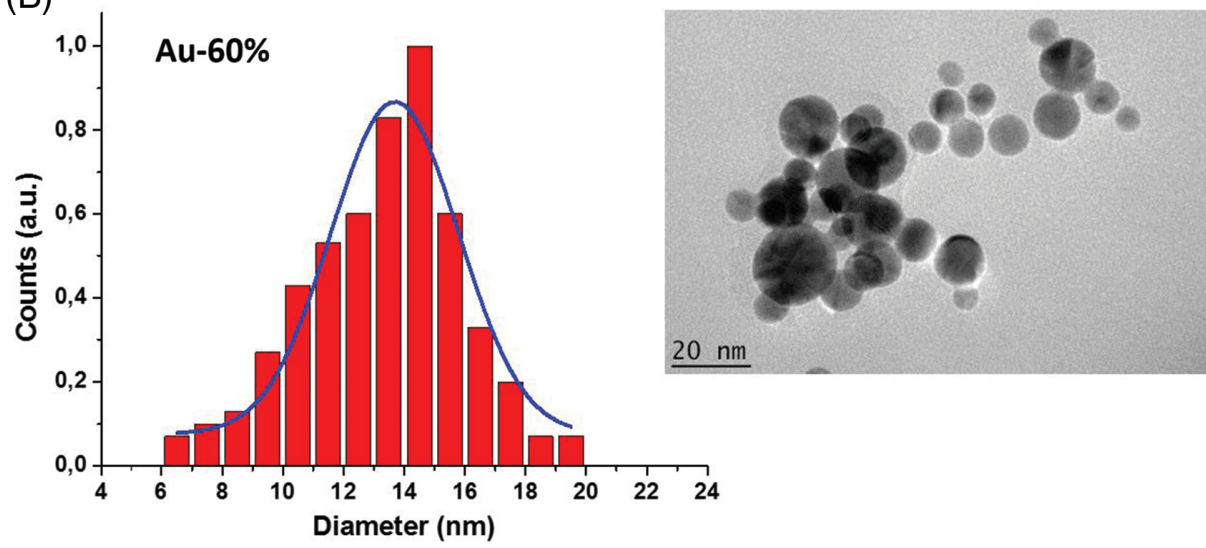

FIGURE 1 HR-TEM images of Au-100\% (100\% Au) (A), Au-60\% (60\% Au/40\% Si) (B) and $\mathrm{Au}-30 \%(30 \% \mathrm{Au} / 70 \% \mathrm{Si})$

(C) prepared by methods of femtosecond laser ablation in water, with corresponding size distribution

(C)

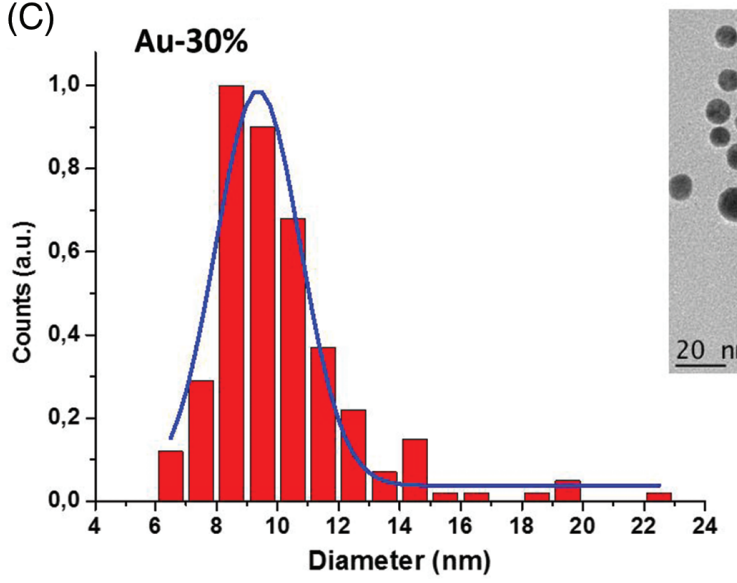


gold. After several minutes of the ablation experiment, a solution of bare Si NPs with concentration of $150 \mu \mathrm{g} / \mathrm{mL}$ was obtained. Then, the gold target was placed into so prepared solutions of Si NPs (preliminarily diluted to concentrations of 45 and $25 \mu \mathrm{g} / \mathrm{mL}$, respectively) and ablated similar to how it was done in case of pure water ambience. As we previously showed [47], such ablation of Au in Si NPs solutions leads to the formation of Au-Si composite NPs and the size of these structures depends on initial concentration of $\mathrm{Si}$ NPs. As shown in Figure 1B,C, composite Au-Si NPs prepared under 25 and $45 \mu \mathrm{g} / \mathrm{mL}$ concentrations of initial $\mathrm{Si}$ colloids had the mean size of 14 and $9 \mathrm{~nm}$, respectively. The decrease of the mean NPs size under the increase of initial Si NPs concentration was explained in our previous paper [47] by the existence of a strong interaction of laser-ablated $\mathrm{Au}$ nanoclusters with already formed water-dispersed $\mathrm{Si}$ NPs, similar to how it happens in the case of biopolymers and other molecules [37, 42]. Here, higher concentration of $\mathrm{Si}$ NPs causes the finalization of $\mathrm{Au}$ nanocluster growth at earlier stages, leading to a smaller mean size of composite NPs [47]. As we also showed from EDX data [47], the content of $\mathrm{Au}$ in NPs composition appears to be inversely proportional to initial concentration of $\mathrm{Si}$ NPs. Therefore, smallest $\mathrm{Au}-\mathrm{Si}$ NPs prepared at higher concentrations of $\mathrm{Si}$ NPs typically have a lower content of $\mathrm{Au}$ in their composition. In this case, NPs typically form core-shell structures with $\mathrm{Au}$ in the core and $\mathrm{Si}$ in the shell [47]. For our experiments, we used 3 types of NPs with different content of Si in their composition: pure Au-100\% NPs (100\% Au); Au$60 \%(60 \% \mathrm{Au} / 40 \% \mathrm{Si})$ and $\mathrm{Au}-30 \%$ (30\% Au/70\% Si). Parameters of these 3 types of NPs are summarized in Table 1.

\subsection{Structural and optical characterization of laser- synthesized nanomaterials}

A high-resolution transmission electron microscope (HRTEM) JEOL 3010 (Japan) operating at $300 \mathrm{kV}$ was used for investigation of the shape and the size of the fabricated Aubased NPs. For this purpose, a drop of freshly prepared colloidal solution was deposited on a carbon-coated copper grid, dried at room temperature and then examined by TEM. The size distribution of Au-based NPs was calculated by ImageJ software (https://imagej.nih.gov/ij/) using 1000 particles. Chemical composition of laser-synthesized NPs was examined by EDX spectroscopy.

RS investigation of freshly prepared NPs was carried out using a confocal Raman system (Ntegra Spectra, NTMDT Corp., Moscow, Russia). An inverted optical scheme implying the excitation and collection of signals from the bottom side of the system was used for sample analysis. An oil immersion objective $(100 \times, 1.3$ NA, Olympus Corporation, Tokyo, Japan) was used for focusing $532 \mathrm{~nm}$ continuous wave $(\mathrm{CW})$ laser radiation on the samples. Laser radiation was set to low power values $(20 \mu \mathrm{W})$ to avoid heating effects during the measurements. The samples were
TABLE 1 Characteristics of Au-based NPs prepared by laser ablation of the gold target in deionized water or Si NPs colloidal solutions

\begin{tabular}{llll} 
Samples & $\begin{array}{l}\text { Initial Si concentration } \\
(\boldsymbol{\mu g} / \mathbf{m L})\end{array}$ & $\begin{array}{l}\text { Mean size, } \\
\mathbf{n m}\end{array}$ & $\mathbf{A u} / \mathrm{Si}$ atomic ratio \\
\hline $\mathrm{Au}-100 \%$ & 0 & 27 & $100 \% \mathrm{Au}$ \\
\hline $\mathrm{Au}-60 \%$ & 25 & 14 & $60 \% \mathrm{Au} / 40 \% \mathrm{Si}$ \\
$\mathrm{Au}-30 \%$ & 45 & 9 & $30 \% \mathrm{Au} / 70 \% \mathrm{Si}$ \\
\hline
\end{tabular}

prepared by dropping NPs solution on $150 \mu \mathrm{m}$ thick borosilicate glass substrate and their subsequent drying at ambient conditions.

\subsection{Rhodamine 6G sample preparation and SERS detection}

Rhodamine 6G (R6G) was mixed with deionized water and diluted into concentration series $(1 \mathrm{mM}-1 \mu \mathrm{M})$. Two microliters of R6G samples were dried into $1.5 \mathrm{~mm}$ polydimethylsiloxane (PDMS) wells placed on top of a silicon wafer or gold-coated polymer-based SERS substrates. Two microliters of Au-based NPs were added on top of the samples. The prepared samples were measured with an in-house built Raman system integrated with a microscope (Olympus) using $785 \mathrm{~nm}$ CW laser excitation. The used integration time was set to 2 seconds with a $40 \times$ objective and $10.5 \mathrm{~mW}$ power at the sample. For the sensitivity testing with 1 to $500 \mu \mathrm{M}$ R6G concentration range, 5 to 30 seconds integration times were used with a $50 \times$ objective and $7.5 \mathrm{~mW}$ laser power at the sample.

\subsection{Immunomagnetic separation beads bound Listeria innocua sample preparations and SERS detection}

The model bacteria (L. innocua ATCC 33090) were grown in LEE Broth, pH $7.2 \pm 0.2$ (Labema Oy, Helsinki, Finland) at $35^{\circ} \mathrm{C}$ for 20 hours. A spectrophotometer HALO DB-20S (Dynamica Scientific Ltd., Newport Pagnell, UK) was used for measuring the concentration. The samples were diluted to achieve bacteria concentrations of $10^{5}$ to $10^{6} \mathrm{cfu} / \mathrm{mL}$ in LEE Broth. The bacteria were captured with anti-Listeria Dynabeads (Life Technologies 71006, Thermo Fisher Scientific Inc., Waltham, MA, USA) and a magnetic particle concentrator (DynaMag-2, Thermo Fisher Scientific Inc., Waltham, MA, USA) was used for the capture as follows: $1 \mathrm{~mL}$ of bacterial culture was incubated with $20 \mu \mathrm{L}$ volume of antiListeria Dynabeads for 10 minutes at room temperature under continuous mixing. The beads were pelleted by a magnet (Dynal MPC-M, Thermo Fisher Scientific Inc., Waltham, MA, USA) onto the side of Eppendorf tubes, supernatants were removed and the samples were rinsed with a washing buffer. The beads were concentrated, the supernatant was removed and the captured bacteria with beads were resuspended into $100 \mathrm{~mL}$ of washing buffer for the SERS detection. The blank Raman spectrum of immunomagnetic 
separation (IMS) beads in LEE Broth can be found in our earlier study [40]. Bacteria spectra were detected with $785 \mathrm{~nm}$ laser excitation, 60 seconds integration time, $50 \times$ objective and $7.5 \mathrm{~mW}$ power. The average SERS spectra were calculated from 30 points measured for each concentration.

\section{5 | Escherichia coli sample preparation and SERS detection}

The model bacteria samples E. coli W3110 (wild-type strain) were grown in standard $250 \mathrm{~mL}$ shaking flasks by using a shaker/incubator device (LT-X series, Kuhner, Switzerland), at approximately $220 \mathrm{rpm}$ and at a temperature of $37^{\circ} \mathrm{C}$. The amount of $100 \mathrm{~mL}$ Yeast Tryptone Phosphate Glucose (2xYTPG) growth medium with $10 \mathrm{~mL}$ of $E$. coli W3110 culture was used for the cultivation in 2 shaking flasks, 1 for the reference and 1 for the actual sample. The optical density respective to the biomass increase at different time spots was measured with a spectrophotometer at $600 \mathrm{~nm}\left(\mathrm{OD}_{600}\right)$. E. coli W3110 cells were harvested after 6 hours of cultivation. The final E. coli W3110 biomass had an $\mathrm{OD}_{600}$ of 5.2. The sample was stored at $+4^{\circ} \mathrm{C}, 3$ times washed in deionized water and centrifuged prior the experiment to remove media traces. Approximately $25 \mu \mathrm{L}$ sample volume was pipetted into a stainless steel cup used for the measurements. Au-based NPs were pipetted on top of the E. coli $\mathrm{W} 3110$ sample. The measurement was performed with a commercial time-gated Raman spectrometer (Timegate Instruments Oy, Oulu, Finland) using pulsed laser excitation at a wavelength of $532 \mathrm{~nm}$. The Raman device was connected to a standard laboratory Raman BWTek RPB 532 probe (B\&W-Tek, Newark, DE, USA) and approximately $25 \mathrm{~mW}$ was used at the sample spot. The signal collection time was set to cover the SERS signal and the fluorescence decay time 1.3 to 1.8 nanoseconds.

\section{6 | Post processing of the SERS spectral data}

The L. innocua ATCC 33090 data was transferred into Matlab 2015a (MathWorks, Natick, MA, USA) with PLS toolbox 2.0 (Eigenvector Research, Inc., Manson, WA, USA) for linear baseline correction. The E. coli W3110 data was analyzed with a spectral processing tool (Timegate Instruments Oy) prior the Matlab plotting. Further data handling and plotting of the figures were performed with OriginPro (V. 2016, OriginLab, Northampton, MA, USA).

\section{3 | RESULTS AND DISCUSSION}

In our experiments, we used 3 types of NPs with decreasing content of $\mathrm{Au}$ in their composition, as shown in Table 1: pure $\mathrm{Au}-100 \%$ NPs $(100 \% \mathrm{Au})$; Au-60\% (60\% Au/40\%Si) and $\mathrm{Au}-30 \%(30 \% \mathrm{Au} / 70 \% \mathrm{Si})$. As shown in Figure 1, Aubased NPs were perfectly spherical in all 3 cases, while the

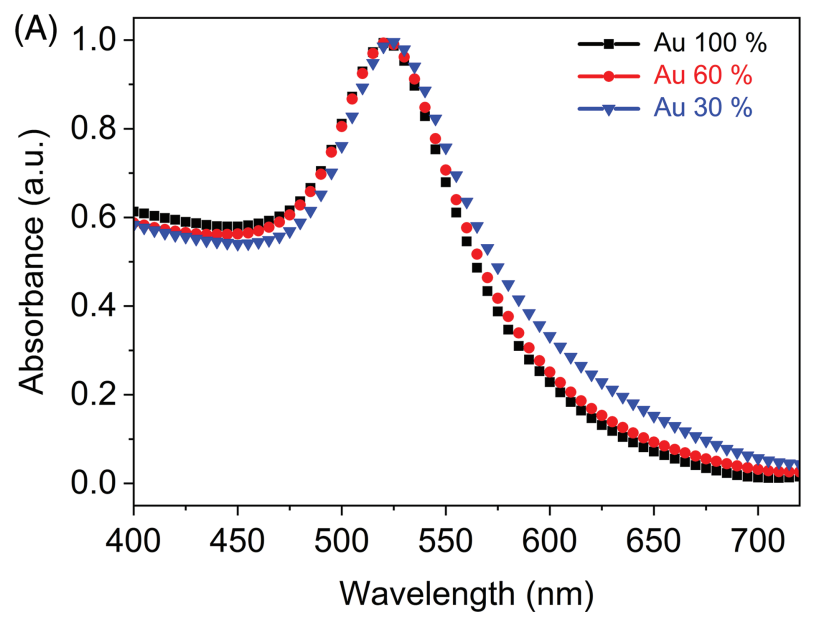

(B)

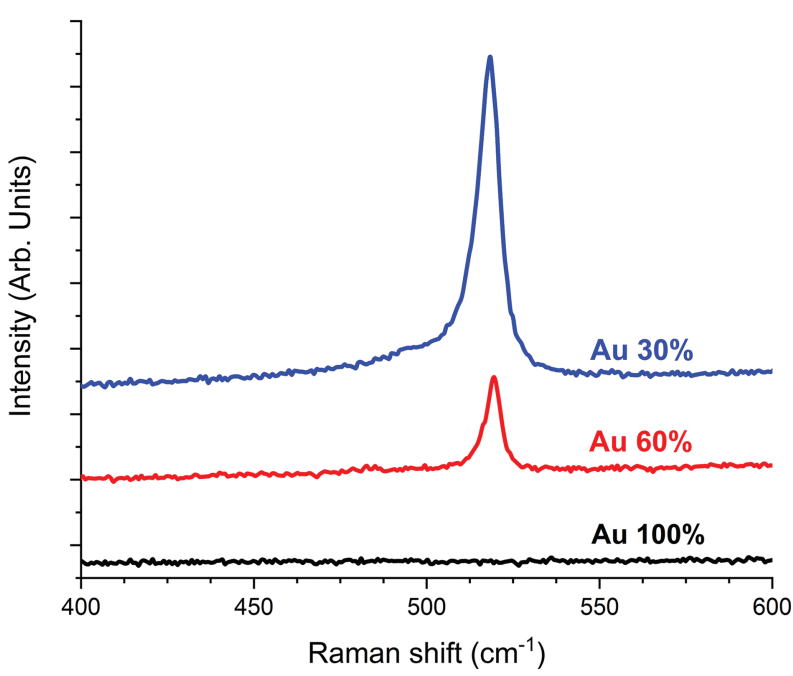

FIGURE 2 Normalized extinction (absorption + scattering) (A) and Raman (B) spectra from laser-synthesized Au-based NPs with different content of $\mathrm{Au}$ in their composition: Au-100\% (black), Au-60 (red) and Au-30\% (blue)

mean size of NPs progressively decreased under the increase of $\mathrm{Si}$ content in NPs composition: $25 \mathrm{~nm}$ (Au100\%), $14 \mathrm{~nm}(\mathrm{Au}-60 \%)$ and $9 \mathrm{~nm}(\mathrm{Au}-30 \%)$.

As shown in Figure 2A, extinction spectra from lasersynthesized Au-based NPs exhibited a characteristic peak around $520 \mathrm{~nm}$, which is normally attributed to free electron oscillations (surface plasmons) over Au NPs. Here, despite a significant content of $\mathrm{Si}$ in the composition of $\mathrm{Au}-60 \%$ and especially Au-30\% NPs in the NPs shell, they still exhibited pronounced peaks associated with the excitations of plasmons over their gold fraction. This experimental fact is very important as it evidences the possibility of plasmonrelated field enhancement even over composite Au-Si structures having a reduced content of plasmonic metal $(\mathrm{Au})$ in their composition. It should be noted that in all 3 cases the plasmonic extinction peak was close to $520 \mathrm{~nm}$, while for $\mathrm{Au}-60 \%$ and $\mathrm{Au}-30 \%$ it was red-shifted (by 1 and $3 \mathrm{~nm}$, respectively), which could be explained by high refractive index of $\mathrm{Si}$ fraction compared to that of the aqueous environment (3.5 RIU over 1.33 RIU) [48].

Figure 2B shows Raman scattering spectra from samples of dried Au-100\%, Au-60\% and Au-30\% NPs deposited on 
glass substrates and measured by a highly sensitive Ntegra Spectra Raman confocal microscopy system. It is visible that Au-100\% NPs did not show any Raman features, which is normal for pure gold NPs samples. However, samples Au$60 \%$ and $\mathrm{Au}-30 \%$ exhibited a strong Raman peak at 520 per $\mathrm{cm}$, which is generally attributed to crystalline $\mathrm{Si}$, while the intensity of this peak increased under the increase of Si content reaching its maximal value for $\mathrm{Au}-30 \%$ samples. Thus, in contrast to pure $\mathrm{Au} \mathrm{NPs,} \mathrm{hybrid} \mathrm{Au}-\mathrm{Si}$ structures exhibited a distinct Si-based Raman line as a new functionality. We believe that this functionality can be employed in biomedical studies, for example, to track the localization of such SERS probes in biological objects (cells) or tissues. Furthermore, it can be used as internal Au-Si NP quality standard.

In our work, the capability of ultrapure laser-synthesized $\mathrm{Au}$ and $\mathrm{Au}-\mathrm{Si}$ NPs to serve as SERS probes was assessed by studying the enhancement of R6G, which was earlier used as a standard test Raman-active molecule [49]. Figure 3 shows SERS spectra (785 nm excitation) of R6G detected with $\mathrm{Au}-100 \%$, Au-60\% and Au-30\% NPs placed in a PDMS well on top of a silicon wafer. One can see that all types of NPs could provide a considerable enhancement of signals from R6G and the recorded enhanced spectra were relatively stable and reproducible for different measurements. The enhancement factor depended on the content of $\mathrm{Au}$ in NPs composition, with the largest enhancement factor for pure $\mathrm{Au}$ NPs (Au-100\%), followed by $\mathrm{Au}-60 \%$ and $\mathrm{Au}-30 \%$ NPs, respectively. Here, even NPs having a dominating content of $\mathrm{Si}(\mathrm{Au}-30 \%)$ were able to enhance Raman signals from R6G. The enhancement of pure Au$100 \%$ NPs was 2 to 5 times and 10 to 15 times larger than in the case of Au- $60 \%$ and Au-30\% NPs, respectively, but the superiority of enhancement for these NPs can be partially explained by a much larger mean size $(27 \mathrm{~nm}$ compared to 14 and $9 \mathrm{~nm}$, respectively). However, it is critically

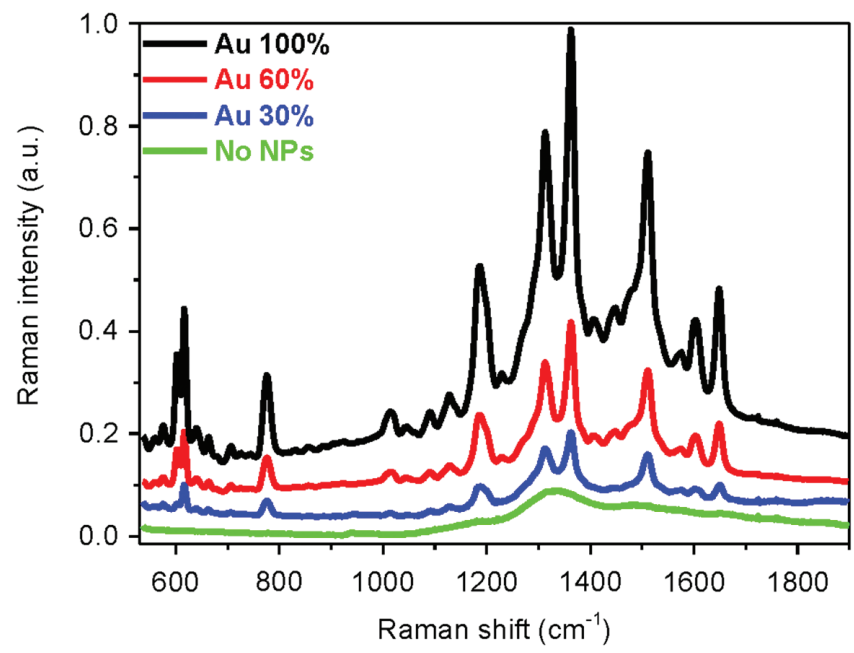

FIGURE 3 Normalized SERS spectra (upon $785 \mathrm{~nm} \mathrm{CW}$ excitation) of $100 \mu \mathrm{M}$ Rhodamine 6G (R6G) detected with different Au-Si compositions (Au-100\%, Au-60\% and Au-30\%) on top of a silicon wafer. The average SERS spectra were calculated from 18 points measured for each concentration important that all 3 types of NPs provided nearly identical enhanced spectral features of R6G. Therefore, the presence of Si content in NPs composition could somewhat decrease the enhancement factor, but these NPs still provided reliable enhancement. This experimental fact gives a promise for the employment of composite Au-Si NPs as SERS probes for tasks of biomolecular identification.

In general, our results unambiguously evidence that laser-synthesized Au-based NPs do generate plasmon enhancement by their own, even if the content of $\mathrm{Au}$ in their composition is relatively low. It should be noted that all enhancement factors were achieved by using $785 \mathrm{~nm}$ wavelength excitation, which is far from the optimal absorption band for the used NPs $(520-525 \mathrm{~nm}$, as follows from Figure 2A). To further maximize the enhancement factor for $785 \mathrm{~nm}$ excitation, we explored the use of these NPs in combination with structured SERS substrates, which had been introduced and described in our previous studies [50]. Such substrates are produced by imprinting of specially profiled patterns on top of a poly(methylmethacrylate) (PMMA) polymer sheet by roll-to-roll UV-nanoimprint lithography, followed by evaporation-based coating of the patterns by a thin layer of gold, and the integration of the structures into hydrophobic PDMS wells [51]. Figure 4A shows SERS spectra of dried $100 \mu \mathrm{M}$ R6G molecules enhanced by Au-60\% and Au-30\% NPs. It is visible that the substrate itself provided a relatively weak signal, while the addition of Au-based NPs led to its drastic enhancement with similar enhancement factors for $\mathrm{Au}-60 \%$ and $\mathrm{Au}-30 \%$ NPs. On the other hand, our data show that the involvement of the substrate led to nearly 10-fold increase of intensity of SERS signals from $100 \mu \mathrm{M}$ R6G using Au-60\% and Au$30 \%$ NPs as Raman probes. Thus, the combination of lasersynthesized Au-based NPs and structured SERS substrate provides a much improved signal enhancement and offers an attractive and versatile SERS-based platform for biological identification. Figure 4B shows the dependence of SERS signal on concentration of R6G using this platform (data are given for Au-60\% NPs). As follows from the spectra, SERS signal amplitude is proportional to the concentration, while the minimal detectable concentration of R6G was lower than $10^{-5} \mathrm{M}$ (under 3 seconds integration time) that is good enough for biological cell sensing.

The applicability of the Au-based NPs for biosensing was studied with 2 different bacteria species. In order to reduce the effect of autofluorescence of the biological cells, we used infrared $(785 \mathrm{~nm})$ wavelength excitation from a $\mathrm{CW}$ laser, which is out of the autofluorescence range of most biological species. Since plasmonic absorption peak does not match $785 \mathrm{~nm}$ wavelength, Au-based NPs were used in combination with a patterned gold-coated substrate to enhance SERS signals. In addition, we used $532 \mathrm{~nm}$ wavelength excitation from a pulsed laser, which fits well the plasmon absorption peak, but appears to be in the range of increased autofluorescence from biological species 


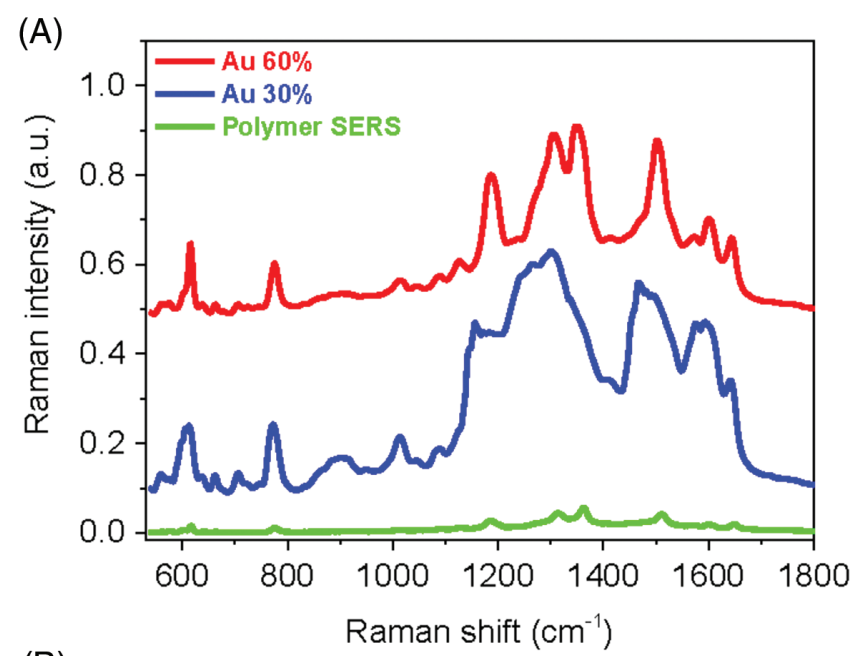

(B)

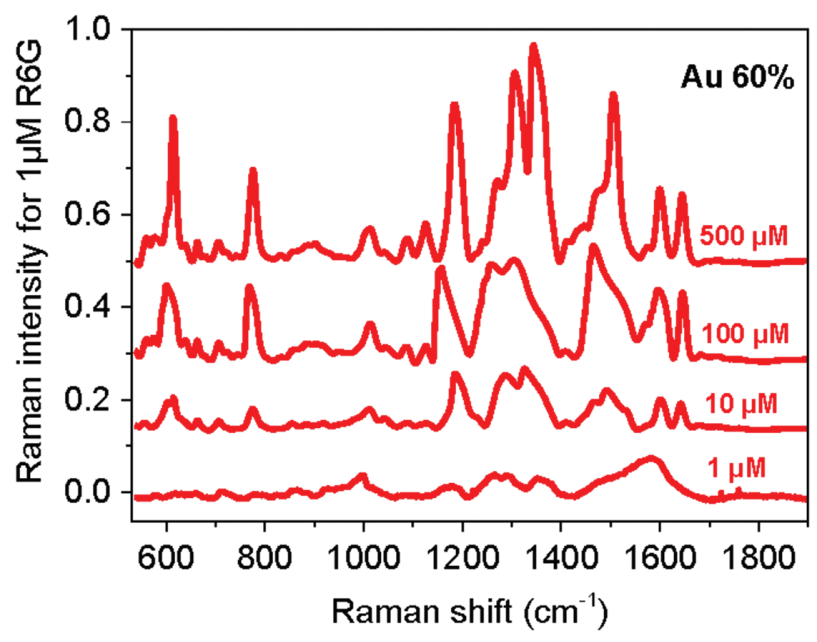

FIGURE 4 A, SERS spectra of $2 \mu \mathrm{L}$ of dried $100 \mu \mathrm{M}$ Rhodamine $6 \mathrm{G}$ (R6G) detected with different Au-Si composition in a $1.5 \mathrm{~mm}$ diameter PDMS well on top of a polymer-based Au-coated SERS substrate. The average SERS spectra were calculated from 18 points measured for each concentration. B, Normalized with integration time SERS spectra of a concentration series of R6G detected using Au-60\% NPs and a polymerbased Au-coated SERS substrate. The average SERS spectra were calculated from 9 points measured for each concentration using $785 \mathrm{~nm}$ CW excitation

(bacterial cells). To solve the autofluorescence problem, we used time-gated detection making possible the suppression of most autofluorescence noises due to picosecond timegated registration of signals [52].

L. innocua ATCC 33090 was the first bacteria of our interest. Bacterial cells were bound to immunomagnetic beads to separate them from the growth broth in order to minimize the effect of the broth on the SERS signal and concentrate the cells. The use of IMS beads typically improves the detection sensitivity by 10 -fold. Our measurements were carried out under $785 \mathrm{~nm}$ excitation using long integration time (60 seconds). Figure 5 shows Raman spectra of $L$. innoсиа ATCC 33090 using the patterned SERS substrate combined with Au-60\% NPs, and the substrate alone. One can find that in both cases we registered similar Raman peaks, including a peak at $737 \mathrm{~cm}^{-1}$, which is characteristic for
L. innocua according to the literature [53, 54]. However, the intensity of the $737 \mathrm{~cm}^{-1}$ Raman peak for the combined detection (SERS substrate plus Au-based NPs) was 4.4 times higher than in the case of SERS substrate alone. Thus, lasersynthesized Au-60\% NPs provided a considerable enhancement of characteristic peak for L. іпnосиа ATCC 33090 even for the excitation wavelength out of their optimal absorption range. It should be noted that even without any special optimization of the measurement procedure using combined SERS substrate-mobile NPs probe platform and nonoptimal excitation wavelength, we were able to achieve the detection limit lower than $10^{5} \mathrm{cfu} / \mathrm{mL}$.

E. coli $\mathrm{W} 3110$ was another example of bacteria used in our analysis. In this case, we explored time-gated Raman detection at a wavelength of $532 \mathrm{~nm}$. E. coli bacteria were taken straight from a growth broth after reaching the stationary phase of the cultivation without a need for IMS beads or the use of an additional SERS substrate. Figure 6 shows SERS spectra of $E$. coli W3110 measured with $532 \mathrm{~nm}$ wavelength excitation. As follows from pink spectrum, without time-gating we could not identify any SERS signal from bacteria due to too high level of autofluorescence noises. However, as shown in the Figure 6, the use of timegating offered an elegant solution of the autofluorescence problem. Green and red spectra show spectra from E. coli alone and E. coli decorated by Au-60\% NPs, respectively. One can see that the employment of NPs led to more than one order of magnitude amplification of SERS signal and thus reveal a variety of novel Raman lines. Among these lines, one can clearly identify the features commonly attributed to E. coli: nucleic acids $\left(666 \mathrm{~cm}^{-1}\right)$, proteins $\left(830 \mathrm{~cm}^{-1}\right)$, vibration bands of Amide III $\left(1200-1300 \mathrm{~cm}^{-1}\right)$ and Amide I $\left(1650 \mathrm{~cm}^{-1}\right)[55,56]$. The peaks around $1650 \mathrm{~cm}^{-1}$ corresponding to the protein $\mathrm{C}=\mathrm{O}$ stretching mode are characteristic for their shape and are often used for calibration in FTIR-measurements [57]. The E. coli W3110 wild-type stain also shows characteristic amino acid spectral lines, such as phenylalanine (around $1000 \mathrm{~cm}^{-1}$ ) and lipids $\left(1447 \mathrm{~cm}^{-1}\right)$. Thus, the laser-synthesized $\mathrm{Au}$ based NPs appear to be efficient SERS probes to detect E. coli at ultra-low quantities with the detection limit lower than $10^{5} \mathrm{cfu} / \mathrm{mL}$.

We believe that the employment of "bare" lasersynthesized Au-based NPs as SERS probes for biomolecular identification can be promising for least 2 reasons. First, these NPs are exempt of ligands or contaminants, which enables one to avoid undesirable Raman signals presenting background noise. Second, phenomena related to quenching of autofluorescence in a studied system due to the direct contact of target biomolecules with metal $[58,59]$ can profit from a high purity of bare laser-synthesized nanomaterials. The advantages of bare nanomaterials were clearly visible during our recent comparative tests involving lasersynthesized NPs and different chemical counterparts, including citrate-coated NPs and gold nanostars, as SERS 


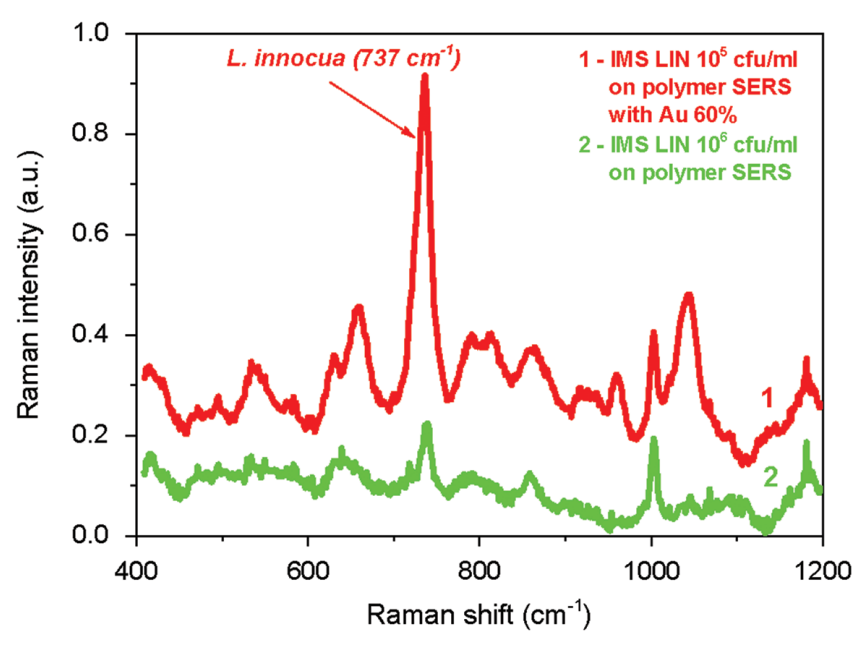

FIGURE 5 Normalized SERS spectra of IMS bead captured L. innocua (IMS LIN) detected using a polymer-based SERS substrate (green) and a combination of the substrate and Au-60\% NPs (red) using $785 \mathrm{~nm} \mathrm{CW}$ excitation

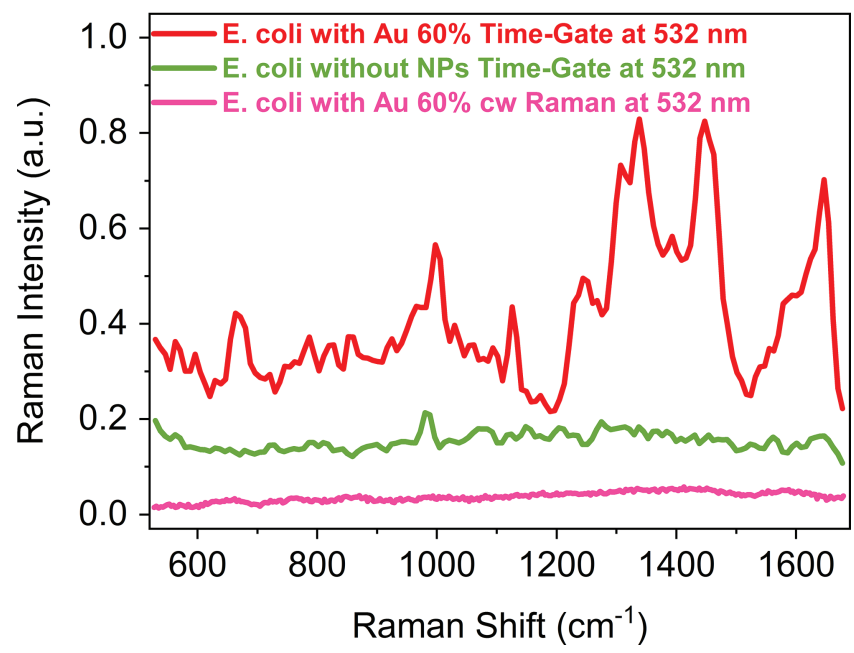

FIGURE 6 SERS spectra of $E$. coli W3110 measured with time-gated Raman using $532 \mathrm{~nm}$ wavelength picosecond pulsed excitation with the use of Au-60\% NPs as Raman probes (red) and without them (green). For comparison we show Raman spectra without time gating (pink)

probes for the identification of beverage spoilage yeasts [41]. As follows from this study, bare laser-synthesized NPs did not provide the strongest enhancement (while the enhancement factor was among the best ones), but they much outperformed all counterparts in terms of signal-tonoise ratio, which is an ultimate parameter describing the performance of SERS probes. As an example, $16 \mathrm{~nm}$ bare NPs were more efficient in terms of this parameter than $10,80,150$ and $200 \mathrm{~nm}$ citrate-coated NPs, as well as $80 \mathrm{~nm}$ nanostars. Notice that after incubation in real biological environment the NPs can be covered by protein corona, which can also provide autofluorescence noise. However, in the case of bare NPs the impact of the protein corona should not be so critical as in the case of ligand-protected counterparts, as the close contact of metal with this corona promises efficient quenching of autofluorescence channel. It should be also noted that the detection limit for bacterial detection in our experiments $\left(10^{5} \mathrm{cfu} / \mathrm{mL}\right)$ was not the lowest compared to the literature. As an example, some references reported the level of detection of the order of $10^{3} \mathrm{cfu} /$ $\mathrm{mL}$ (see, ref. [9]). However, to the best of our knowledge, this level was observed with Ag NPs, which are known to be the champions in plasmonic enhancement, but cannot be used for in situ control of biological object of interest due to low biocompatibility (Ag NPs are known to be very harmful $[60,61])$. In contrast, the presented bare Au-based nanoformulations are supposed to provide this lowdisturbing option. In addition, we believe that after a proper optimization of the measurement system (laser wavelength, substrate-based or substrate-free geometry, composition, size and architectures of used nanoformulations) lasersynthesized NPs could provide much improved detection limit, as it was demonstrated in our recent paper [41].

The efficient enhancement of electric field and demonstration of SERS effect for AuSi composites is another important result. As we explained above, $\mathrm{Si}$ and its compounds are among the best inorganic materials from the point of view of non-disturbing character of interaction with biological systems. As an example, some previous studies used designed SERS probes based on silica $\left(\mathrm{SiO}_{2}\right)$-coated plasmonic structures, including gold nanorods and nanostars [62-64], to improve the biocompatibility and efficiency of SERS probes. The inclusion of nonoxidized crystalline silicon ( $\mathrm{Si}$ ) fraction into composition of SERS probes is expected to further improve the biocompatibility of these probes, as $\mathrm{Si}$ is one of the essential materials in biological systems, which does not provoke any toxic effects even under massive injection in vitro or in vivo [44-46]. In addition, in contrast to silica, silicon can provide a distinct Raman scattering peak around $520 / \mathrm{cm}$, which was clearly visible in our tests (Figure 2(B)). This distinct Raman feature of Au-Si NPs promises a new attractive functionality in SERS studies related to the possibility of their tracking in biological objects (cells) or tissues, for example, to clarify the distribution of the probes in different living cell compartments.

\section{4 | CONCLUSION}

We explored the employment of bare (ligand-free) Au-based nanomaterials, including pure Au NPs and Au-Si composite NPs, synthesized by methods of laser ablation in deionized water, as SERS probes for bacteria detection. We first characterized and examined these NPs using standard Raman active molecules (R6G). Our experiments showed that the enhancement factor depends on the content of $\mathrm{Au}$ in NPs composition, being the largest for pure Au NPs (Au-100\%), followed by Au-60\% and Au-30\% NPs, respectively. On the other hand, Au- $60 \%$ and Au-30\% NPs provided a characteristic Raman line of crystalline Si around $520 \mathrm{~cm}^{-1}$, which can be used for their tracking. We finally used the NPs for 
the detection of bacteria, L. innocua ATCC 33090 and E. coli $\mathrm{W} 3110$, with a detection limit below $10^{5} \mathrm{cfu} / \mathrm{mL}$. We suppose that the employment of ultrapure (contamination-free), ligand-free Au-based NPs, having much improved biocompatibility compared to chemically synthesized counterparts, can open up opportunities for nondisturbing studies of live biological systems such as bacterial and cell cultures.

\section{ACKNOWLEDGMENTS}

M.K. acknowledges the support by Academy of Finland through FOULSENS project (292253). Y.V. R. acknowledges a support from European Cooperation in Science and Technology project (ECOST-STSM-BM1205-120416-072252) and from Center for Research Strategy of Free University of Berlin (0503121810) for performing experiments. S.U. acknowledges the financial support by Academy of Finland through M-SPEC project (284907). A.P. acknowledges Academy of Finland (projects 260321, 290596). This work was also partially supported by Government of Russian Federation, Grant 074-U01 and the Competitiveness Program of NRNU MEPhI. Y.V.R., A.P., G.T., A.V.K. acknowledge contributions from "LASERNANOCANCER" (No. PC201420) and GRAVITY projects of the ITMO "Plan Cancer 2014-2019" INSERM program.

\section{ORCID}

Martin Kögler (1D http://orcid.org/ 0000-0003-2154-8879

Andrei V. Kabashin (ID http://orcid.org/ 0000-0003-1549-7198

\section{REFERENCES}

[1] M. Schmitt, J. Popp, J. Raman Spectrosc. 2006, 37, 20.

[2] S. Nie, S. R. Emory, Science 1997, 275, 1102.

[3] J. Kneipp, H. Kneipp, W. Burghardt, K. Kneipp, Nano Lett. 2007, 7, 2819.

[4] M. Harz, P. Rosch, J. Popp, Cytometry A 2009, 75, 104.

[5] R. M. Jarvis, R. Goodacre, Chem. Soc. Rev. 2008, 37, 931.

[6] R. M. Jarvis, R. Goodacre, Anal. Chem. 2004, 76, 40.

[7] C. Fan, Z. Hu, A. Mustapha, M. Lin, Appl. Microbiol. Biotechnol. 2011, 92, 1053.

[8] E. Temur, I. H. Boyaci, U. Tamer, H. Unsal, N. Aydogan, Anal. Bioanal. Chem. 2010, 397, 1595.

[9] L. Chen, N. Mungroo, L. Daikuara, S. Neethirajan, J. Nanobiotechnology 2015, 13, 45.

[10] H. Zhou, D. Yang, N. P. Ivleva, N. E. Mircescu, R. Niessner, C. Haisch, Anal. Chem. 2014, 86, 1525.

[11] A. Sengupta, M. Mujacic, E. J. Davis, Anal. Bioanal. Chem. 2006, 386, 1379.

[12] S. P. Ravindranath, Y. Wang, J. Irudayaraj, Sensors Actuators B Chem. 2011, 152,183

[13] M. N. Adam, O. Gustavo, N. Suresh, Microchim. Acta 2015, 183, 697.

[14] D. P. Cowcher, Y. Xu, R. Goodacre, Anal. Chem. 2013, 85, 3297.

[15] R. Wilson, P. Monaghan, S. A. Bowden, J. Parnell, J. M. Cooper, Anal. Chem. 2007, 79, 7036

[16] R. Prucek, V. Ranc, L. Kvitek, A. Panacek, R. Zboril, M. Kolar, Analyst 2012, 137, 2866.

[17] Y. Liu, Y.-R. Chen, X. Nou, K. Chao, Appl. Spectrosc. 2007, 61, 824.

[18] M. Knauer, N. P. Ivleva, R. Niessner, C. Haisch, Anal. Sci. 2010, 26, 761.
[19] H. Zhou, D. Yang, N. P. Ivleva, N. E. Mircescu, S. Schubert, R. Niessner, A. Wieser, C. Haisch, Anal. Chem. 2015, 87, 6553.

[20] M. Brust, M. Walker, D. Bethell, D. J. Schiffrin, R. Whyman, J. Chem. Soc. Chem. Commun. 1994, 7, 801.

[21] G. Frens, Nat. Phys. Sci. 1973, 241, 20.

[22] S. K. Balasubramanian, L. Yang, L. Y. Yung, C. N. Ong, W. Y. Ong, L. E. Yu, Biomaterials 2010, 31, 9023.

[23] P. Mukherjee, A. Ahmad, D. Mandal, S. Senapati, S. R. Sainkar, M. I. Khan, R. Parishcha, P. V. Ajaykumar, M. Alam, R. Kumar, M. Sastry, Nano Lett. 2001, 1, 515.

[24] S. Chatterjee, A. Bandyopadhyay, K. Sarkar, J. Nanobiotechnology 2011, 9, 7.

[25] A. M. Alkilany, C. J. Murphy, J. Nanopart. Res. 2010, 12, 2313.

[26] L. Cui, P. Chen, S. Chen, Z. Yuan, C. Yu, B. Ren, K. Zhang, Anal. Chem. 2013, 85, 5436.

[27] M. R. El-Zahry, A. Mahmoud, I. H. Refaat, H. A. Mohamed, H. Bohlmann, B. Lendl, Talanta 2015, 138, 183.

[28] A. Fojtik, M. Giersig, A. Henglein, Ber. Bunsenges. Phys. Chem. 1993, 252, 1493.

[29] M. S. Sibbald, G. Chumanov, T. M. Cotton, J. Phys. Chem. B 1996, 100, 4672.

[30] F. Mafune, J. Kohno, Y. Takeda, T. Kondow, J. Phys. Chem. B 2001, 105, 5114.

[31] A. V. Kabashin, M. Meunier, J. Appl. Phys. 2003, 94, 7941.

[32] A. V. Kabashin, M. Meunier, J. Phys. Conf. Ser. 2007, 59, 354.

[33] A. Kabashin, P. Delaporte, A. Pereira, D. Grojo, R. Torres, T. Sarnet, M. Sentis, Nanoscale Res. Lett. 2010, 5, 454.

[34] D. Zhang, B. Gökce, S. Barcikowski, Chem. Rev. 2017, 117, 3990.

[35] S. Besner, A. V. Kabashin, M. Meunier, Appl. Phys. Lett. 2006, 89, 233122.

[36] K. Maximova, A. Aristov, M. Sentis, A. V. Kabashin, Nanotechnology 2015, 26, 065601.

[37] J.-P. Sylvestre, S. Poulin, A. V. Kabashin, E. Sacher, M. Meunier, H. T. Luong, J. Phys. Chem. B 2004, 108, 16864.

[38] P. Wagener, A. Schwenke, S. Barcikowski, Langmuir 2012, 28, 6132.

[39] S. Hebié, Y. Holade, K. Maximova, M. Sentis, P. Delaporte, K. B. Kokoh, T. W. Napporn, A. V. Kabashin, ACS Catal. 2015, 5, 6489.

[40] S. Uusitalo, M. Kögler, A. L. Välimaa, A. Popov, Y. Ryabchikov, V. Kontturi, S. Siitonen, J. Petäjä, T. Virtanen, R. Laitinen, M. Kinnunen, I. Meglinski, A. Kabashin, A. Bunker, T. Viitala, J. Hiltunen, RSC Adv. 2016, 6, 62981.

[41] S. Uusitalo, A. Popov, Y. V. Ryabchikov, O. Bibikova, H.-L. Alakomi, R. Juvonen, V. Kontturi, S. Siitonen, A. Kabashin, I. Meglinski, J. Hiltunen, A. Laitila, J. Food Eng. 2017, 212, 47.

[42] F. Correard, K. Maximova, M. A. Esteve, C. Villard, M. Roy, A. Al-Kattan, M. Sentis, M. Gingras, A. V. Kabashin, D. Braguer, Int. J. Nanomedicine 2014, 9, 5415.

[43] Y. He, Y. Su, Silicon Nano-Biotechnology, Springer: Heidelberg, 2014, p. 39.

[44] A. Al-Kattan, Y. V. Ryabchikov, T. Baati, V. Chirvony, J. F. Sánchez-Royo, M. Sentis, D. Braguer, V. Y. Timoshenko, M.-A. Estève, A. V. Kabashin, J. Mater. Chem. B 2016, 4, 7852.

[45] K. P. Tamarov, L. A. Osminkina, S. V. Zinovyev, K. A. Maximova, J. V. Kargina, M. B. Gongalsky, Y. Ryabchikov, A. Al-Kattan, A. P. Sviridov, M. Sentis, A. V. Ivanov, V. N. Nikiforov, A. V. Kabashin, V. Y. Timoshenko, Sci. Rep. 2014, 4, 7034.

[46] T. Baati, A. Al-Kattan, M. A. Esteve, L. Njim, Y. Ryabchikov, F. Chaspoul, M. Hammami, M. Sentis, A. V. Kabashin, D. Braguer, Sci. Rep. 2016, 6, 25400.

[47] Y. V. Ryabchikov, A. A. Popov, M. Sentis, V. Y. Timoshenko, A. V. Kabashin, Proc. SPIE 2016, 9737, 97370F.

[48] P. K. Jain, K. S. Lee, I. H. El-Sayed, M. A. El-Sayed, J. Phys. Chem. B 2006, 110, 7238.

[49] D. Zhang, Y. Xie, S. K. Deb, V. Jo Davison, D. Ben-Amotz, Anal. Chem. 2005, 77, 3563.

[50] S. Uusitalo, J. Hiltunen, P. Karioja, S. Siitonen, V. Kontturi, R. Myllyla, M. Kinnunen, I. Meglinski, J. Eur. Opt. Soc. Rapid Publ. 2015, 10,8 .

[51] S. Z. Oo, R. Y. Chen, S. Siitonen, V. Kontturi, D. A. Eustace, J. Tuominen, S. Aikio, M. D. Charlton, Opt. Express 2013, 21, 18484. 
[52] J. Kostamovaara, J. Tenhunen, M. Kögler, I. Nissinen, J. Nissinen, P. Keranen, Opt. Express 2013, 21, 31632.

[53] B. S. Luo, M. Lin, J. Rapid Methods Autom Microbiol 2008, 16, 238.

[54] K. Kairyte, Z. Luksiene, V. Sablinskas, Chem. Technol. 2012, 61, 46.

[55] I. Notingher, Sensors 2007, 7, 1343.

[56] D. Yang, H. Zhou, C. Haisch, R. Niessner, Y. Ying, Talanta 2016, $146,457$.

[57] S. Vonhoff, J. Condliffe, H. Schiffter, J. Pharm. Biomed. Anal. 2010, 51, 39.

[58] L. Dong, F. Ye, J. Hu, S. Popov, A. T. Friberg, M. Muhammed, J. Eur. Opt. Soc. 2011, 6, 11019.

[59] E. Dulkeith, M. Ringler, T. A. Klar, J. Feldmann, A. Munoz Javier, W. J. Parak, Nano Lett. 2005, 5, 585.

[60] P. V. AshaRani, G. Low Kah Mun, M. P. Hande, S. Valiyaveettil, ACS Nano 2009, 3, 279.

[61] O. Bar-Ilan, R. M. Albrecht, V. E. Fako, D. Y. Furgeson, Small 2009, 5, 1897.

[62] A. M. Fales, H. Yuan, T. Vo-Dinh, Mol. Pharm. 2013, 10, 2291.
[63] D. Rodríguez-Fernández, J. Langer, M. Henriksen-Lacey, L. M. Liz-Marzán, Chem. Mater. 2015, 27, 2540-2545.

[64] S. Lai, S. Centi, C. Borri, F. Ratto, L. Cavigli, F. Micheletti, B. Kemper, S. Ketelhut, T. Kozyreva, L. Gonnelli, F. Rossi, S. Colagrande, R. Pini, Colloids Surf. B. Biointerfaces 2017, 157, 174.

\section{How to cite this article: Kögler $M$,} Ryabchikov YV, Uusitalo $S$, et al. Bare lasersynthesized Au-based nanoparticles as nondisturbing surface-enhanced Raman scattering probes for bacteria identification. J. Biophotonics. 2018;11: e201700225. https://doi.org/10.1002/jbio.201700225 